\title{
Suppression of wingless-type MMTV integration site family, member 1 expression by small interfering RNA inhibits U251 glioma cell growth in vitro
}

\author{
LUN DONG $^{1}$, XIAO-CHUN DUAN ${ }^{1}$, CHONG-XU HAN $^{2}$, HENGZHU ZHANG $^{1}$ and YONGKANG WU ${ }^{1}$ \\ ${ }^{1}$ Department of Neurosurgery and ${ }^{2}$ Central Laboratory, Clinical Medical College of Yangzhou University, \\ Yangzhou, Jiangsu 225001, P.R. China
}

Received July 4, 2013; Accepted January 3, 2014

DOI: $10.3892 / \mathrm{ol} .2014 .2647$

\begin{abstract}
A Wingless-type MMTV integration site family, member 1 (Wnt-1) RNA interference expression vector was constructed during the present study, which was used to transfect the glioma U251 cell line and investigate its effect on glioma. Two 21-base oligonucleotides complementary to the coding sequence that was flanking the loop sequence were designed to form a DNA hairpin template for the target small interfering RNA (siRNA). The siRNA templates were cloned into the siRNA expression vector, pGPU6/green fluorescent protein (GFP)/Neo and the sequence was confirmed by DNA sequencing. The pGPU6/GFP/Neo-short hairpin RNA (shRNA)-Wnt-1 vector was subsequently transfected into U251 cells, and reverse transcription polymerase chain reaction and western blot analysis were used to evaluate the Wnt-1 gene silencing effect on U251 cell growth by MTT assay and flow cytometry. The Wnt-1 protein expression was significantly reduced following transfection with the recombinant plasmid, as determined by western blot analysis of the transfected U251 cells. This transfection exhibited a significantly higher death rate, as shown by MTT. Thus, the present study demonstrated that the pGPU6/GFP/Neo-shRNA-Wnt-1 vector inhibited Wnt-1 protein expression. However, further investigations regarding the Wnt signaling pathway in glioma pathogenesis are required.
\end{abstract}

Correspondence to: Professor Hengzhu Zhang, Department of Neurosurgery, Clinical Medical College of Yangzhou University, 98 Nan Tong Xi Lu, Yangzhou, Jiangsu 225001, P.R. China E-mail: dongluen@163.com; lundongu571@163.com

Key words: wingless-type MMTV integration site family, member 1, RNA interference, glioma, plasmid, U251 cells, proliferation

\section{Introduction}

Wingless-type MMTV integration site, member 1 (Wnt-1), the first identified member of the Int- 1 family, was named by Nusse in 1991 (1). The first Int-1 was termed Wnt-1, as Int-1 and the Wnt gene family were homologous. The Wnt-1 gene consists of 805 adenines, 1,523 cytosines, 1,320 guanines and 874 thymines. Current studies have proposed that the Wnt-1 protein controls cell growth, proliferation, secretion of key signaling molecules, mediates information flow between cells and stem cells, and is important in neural development. Wnt-1 gene expression has been found to closely correlate with the development of numerous types of tumor (1-7). You et al (8), as well as other studies, have also indicated that Wnt-1-target genes may be potential cancer therapy targets $(9,10)$. Preliminary experiments in the present study found that the Wnt-1 protein expression in human glioma was significantly higher than in normal brain tissue, and is closely associated with the degree of malignancy. Therefore, the aim of the current study was to further investigate the role of Wnt-1 in glioma by RNA interference (RNAi) targeting.

\section{Materials and methods}

Materials. U251 glioma cells were purchased from the Cell Bank of the Shanghai Institute of Biochemistry and Cell Biology (Shanghai, China). The vectors used were as follows: pGPU6/green fluorescent protein (GFP)/Neo-short hairpin RNA (shRNA)-GAPDH served as a positive control and pGPU6/GFP/Neo-shNC served as a negative control. The pGPU6/GFP/Neo expression plasmid was purchased from Wuhan Genesil Biotechnology Co., Ltd (Wuhan, China). Transfections were performed using liposome Lipofectamine $^{\mathrm{TM}} 2000$ reagent and TRIzol that were purchased from Life Technologies (Foster City, CA, USA). The Wnt-1 primary antibody was obtained from Neomarkers Inc. (Fremont, CA, USA), while the horseradish peroxidase-conjugated monoclonal goat anti-rabbit secondary antibody was purchased from ZhongShan Bio-Tech Co., Ltd. (Guangzhou, China). High glucose Dulbecco's Modified Eagle's Medium (DMEM) was purchased from Life Technologies and fetal calf serum was purchased from Hangzhou Sijiqing Biological 
Engineering Materials Co., Ltd. (Hangzhou, China). The restriction enzymes (BamHI, Pst I and BbsI), DNA markers, agarose gel DNA purification kit version 2.0, T4 DNA ligase Taq DNA polymerase and polymerase chain reaction (PCR) primers were purchased from Takara Bio, Inc. (Shiga, Japan). Little mention plasmid kit, and propidium iodide (PI) and MTT reagents were purchased from Beyotime Institute of Biotechnology (Nantong, China). M-MLV reverse transcriptase was purchased from Promega Corporation (Madison, WI, USA).

Small interfering RNA (siRNA) target sequence design. The full-length Wnt-1 gene sequence was retrieved from GenBank (NM_005430) and the siRNA design principles were obtained from Takara Biotechnology special siRNA design software [Takara Biotechnology (Dalian) Co., Ltd., Dalian, China) to select a 21-nt siRNA target template. The shRNA selected TTCAAGAGA loop structure was maintained to avoid formation of a termination signal and the shRNA transcription termination sequence was composed of a T6 structure. CACC was added to the sense strand of the template to form a $B b s$ I complementary sticky end and antisense strand template. GATC was added to the $5^{\prime}$ end and was digested with BamHI to generate complementary sticky ends. When the first siRNA base was not a $\mathrm{G}$, then an additional CACC was added after the $\mathrm{G}$. The following primers were used: Sense, 5'-ACGGCGTTTATC TTCGCTATC-3' and antisense, 3'-TGCCGCAAATAGAAG CGATAG-5' for Wnt-1. The following hairpin single-stranded oligonucleotide sequence was then designed and synthesized: Sense, 5'-CACCGACGG CGTTTATCTTCGCTATCTTCAAGAGAGATAGCGAAG ATAAACGCCGTTTTTTTG-3' and antisense, 5'-GATCCA AAAAAACGGCGTTTATCTTCGCTATCTCTCTTGAAG ATAGCGAAGATAAACGCCGTC-3' for Wnt-1. The oligonucleotides were synthesized by the Shanghai Jima Company (Shanghai, China).

Construction of Wnt-1 targeting pGPU6/GFP/Neo-Wnt-1 vector for RNAi. Synthetic single-stranded oligonucleotides were dissolved in Tris-EDTA buffer ( $\mathrm{pH} 8.0 ; 10 \mathrm{mM}$ Tris- $\mathrm{HCl}$, $1 \mathrm{mM}$ EDTA), diluted to $100 \mu \mathrm{mol} / 1$ and annealed to form an shRNA template ( $5 \mu 1$ justice chain, $5 \mu 1$ antisense strand, $5 \mu \mathrm{l}$ annealing buffer and $35 \mu \mathrm{l}$ double distilled (dd) $\mathrm{H}_{2} \mathrm{O}$ to a 50- $\mu$ l total volume). The shRNA template was annealed on a PCR instrument (ABI7900HT, Invitrogen Applied Biosystems, Foster City, CA, USA) according to the following procedure: $95^{\circ} \mathrm{C}$ for $5 \mathrm{~min}, 85^{\circ} \mathrm{C}$ for $5 \mathrm{~min}, 75^{\circ} \mathrm{C}$ for $5 \mathrm{~min}$ and $70^{\circ} \mathrm{C}$ for $5 \mathrm{~min}$. The template was stored at $4^{\circ} \mathrm{C}$ to generate a $10-\mu \mathrm{M}$ concentration of shRNA. The template solution was diluted 500-fold to a final concentration of $20 \mathrm{nM}$ for ligation. Restriction digestions were performed with $2 \mu \mathrm{g}$ pGPU6/GFP/Neo, according to the following conditions: $5 \mu \mathrm{l} 10 \mathrm{X}$ buffer $\mathrm{G}$ (Shanghai PureOne Biotechnology Co., Shanghai, China), $2 \mu \mathrm{l}$ BbsI enzyme, $2 \mu \mathrm{l} \mathrm{BamHI}$ enzyme, $2 \mu \mathrm{g}$ pGPU6/GFP/Neo and $\mathrm{ddH}_{2} \mathrm{O}$ to a total volume of $50 \mu \mathrm{l}$. Following digestion at $37^{\circ} \mathrm{C}$ for $1 \mathrm{~h}$, the product concentrations were examined by agarose gel electrophoresis, using the agarose gel DNA purification kit version 2.0 and diluted to $50 \mathrm{ng} / \mu \mathrm{l}$. Ligations were performed in $2 \mu \mathrm{l} 10 \mathrm{X}$ T4 ligation buffer, $1 \mu 1$ pGPU6/GFP/Neo $(B b s \mathrm{I}+$ BamHI), $1 \mu \mathrm{l}$ shRNA template, $0.5 \mu \mathrm{l}$ T4 DNA ligase (5 Weiss U/ $\mu \mathrm{l}$ ) and

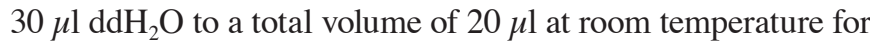
$2 \mathrm{~h}$.

Plasmid identification. Competent Escherichia coli DH5 $\alpha$ cells were grown on lysis buffer medium plates containing kanamycin (Beyotime Institute of Biotechnology) at $37^{\circ} \mathrm{C}$ for $18 \mathrm{~h}$. Six colonies were selected and used to inoculate the kanamycin-containing LB liquid medium $(50 \mu \mathrm{g} / \mathrm{ml})$, which was agitated using a blender (Beijing Tianshi Tianli Medical Device Technology Development Center, Beijing, China) overnight. The plasmids were extracted by alkaline lysis and digested sequentially with Bam HI and PstI. The positive recombinant vectors were digested with $B a m \mathrm{HI}$, but not PstI. Two clones were selected for each vector and sequenced by Invitrogen Applied Biosystems (Shanghai, China).

Cell culture. The U251 cell lines were grown at $37^{\circ} \mathrm{C}$ in a $5 \%$ $\mathrm{CO}_{2}$ humidified atmosphere with high glucose DMEM medium (containing 10\% fetal bovine serum (FBS), $100 \mathrm{U} / 1$ penicillin, $100 \mathrm{mg} / \mathrm{l}$ streptomycin and $10 \%$ fetal calf serum).

Plasmid transfection. Transfected cells $\left(3 \times 10^{5}\right)$ were grown to $70-80 \%$ confluence for two days, and subsequently inoculated in six-well plates $(35 \mathrm{~mm}$ ), with $2 \mathrm{ml} \mathrm{10 \%} \mathrm{FBS} \mathrm{(Chongqing}$ Manuik Technology Co.,Ltd., Chongqing, China) perwell.Prior to transfection, the liposome/DNA was incubated for $10 \mathrm{~min}$, and replaced with $1 \mathrm{ml}$ fresh serum-free 10\% FBS (Chongqing Manuik Technology Co., Ltd.). Based on the pretest results, the cells were cultured with Lipofectamine ${ }^{\mathrm{TM}} 2000$ reagent (Life Technologies) and plasmid at a ratio of $6 \mu \mathrm{l}: 2 \mu \mathrm{g}$, respectively, according to the manufacturer's instructions, and incubated at $37^{\circ} \mathrm{C}$ in a $5 \% \mathrm{CO}_{2}$ humidified atmosphere. After $5 \mathrm{~h}, 2-3 \mathrm{ml}$ fresh growth medium was added. The cells were collected the next day and fresh $10 \%$ fetal calf serum was added. The cells were then cultured for $48 \mathrm{~h}$ to observe any GFP expression. The cells were divided into the following four transfection groups: pGPU6/GFP/Neo-Wnt-1, pGPU6/GFP/Neo-shRNA-GAPDH (positive control), pGPU6/GFP/Neo-shNC (negative control) and a phosphate-buffered saline (PBS) control. GFP expression was used to evaluate the transfection efficiency $48 \mathrm{~h}$ following transfection and was measured by 488-nm excitation via fluorescence microscopy (Olympus BX51; Olympus America Inc., Center Valley, PA, USA).

Reverse transcription (RT)-PCR detection of Wnt-1 $m R N A$ expression level. The primer design software Premier 5.0 (Premier Biosoft, Palo Alto, CA, USA) was used to design the following primers: Sense, 5'-CTGCCTCTCTTCTTCCCCTT-3' and antisense, 5'-TCACAGCTGT TCAATGGCTC-3' for Wnt-1 (251-bp product); and sense, 5'-CCATGT TCGTCATGGGTGTGAACCA-3' and antisense, 5'-GCCAGT AGAGGCAGGGATGATGTTC-3' for the internal reference, GAPDH (246-bp product). Preamplification of GAPDH was used to assess the efficacy of RT, with a semi-quantitative $\mathrm{PCR}$ reaction run in parallel, which served as an internal reference. TRIzol was used to extract the total cellular RNA and first-strand cDNA synthesis was performed according to the manufacturer's instructions. The total RNA $(2 \mu \mathrm{g})$ was used for RT, in addition, $0.1 \mu \mathrm{g}$ oligo-dt, denatured at $65^{\circ} \mathrm{C}$ for 
$10 \mathrm{~min}$ and placed immediately in an ice bath for $5 \mathrm{~min}$, was added to $5 \mu 15 \mathrm{X}$ PCR buffer [Takara Biotechnology (Dalian) Co., Ltd.], $1 \mu 1 \mathrm{dNTP}$ (10 mM each), 100 units RNAsin, 10 units M-MLV reverse transcriptase and water, which was added to produce a total volume of $25 \mu \mathrm{l}$. The samples were incubated at $42^{\circ} \mathrm{C}$ for $60 \mathrm{~min}$ following a 5 -min $95^{\circ} \mathrm{C}$ denaturalization step, subsequently placed in an ice bath for 3 min and stored at $-20^{\circ} \mathrm{C}$ to conserve the RNA template for the PCR. The RNA template was then converted into cDNA for use in the RT-PCR, which was performed in a total reaction volume of $50 \mu \mathrm{l}$, containing $5 \mu \mathrm{l} 10 \mathrm{X}$ buffer, $4 \mu 1 \mathrm{MgCl}_{2}$ (25 mM), $1 \mu \mathrm{l}$ dNTP (10 mM each), $0.5 \mu l$ primer (50 pmol $/ \mu \mathrm{l})$, $0.5 \mu 1$ downstream primer $(50 \mathrm{pmol} / \mu \mathrm{l}), 0.3 \mu \mathrm{l}$ Taq enzyme (5 U/ $\mu \mathrm{l}), 2 \mu \mathrm{l}$ cDNA template and 30-50 $\mu \mathrm{l}$ paraffin oil. PCR reactions were performed as follows: $95^{\circ} \mathrm{C}$ denaturation for $5 \mathrm{~min} ; 30$ cycles of $94^{\circ} \mathrm{C}$ for $30 \mathrm{sec}, 50^{\circ} \mathrm{C}$ annealing for $30 \mathrm{sec}$ and $72^{\circ} \mathrm{C}$ for $1 \mathrm{~min}$; with a final step at $72^{\circ} \mathrm{C}$ for $5 \mathrm{~min}$. The products were subjected to $2 \%$ agarose electrophoresis and ethidium bromide staining. Images were captured using the IBM 586 computer-controlled Gel Doc 1000 imaging system (Bio-Rad, Hercules, CA, USA).

Western blot analysis. Western blot analysis was used to detect Wnt-1 protein expression prior to and following U251 transfection. Total cellular protein was determined by SDS-PAGE gel electrophoresis. The proteins were transferred to nitrocellulose membranes (Whatman Inc., London, UK) for protein immunoassays and the primary monoclonal mouse anti-human proto-onocogene Wnt-1 antibody (Boster Biotechnology Co., Ltd., Wuhan, China) was used at a dilution of 1:100, with the secondary monoclonal rabbit anti-mouse antibody (Boster Biotechnology Co., Ltd.) at 1:500.

MTT cell proliferation assay. U251-transfected cells were subjected to trypsin digestion following $24 \mathrm{~h}$. Single cell suspensions were prepared in culture medium containing $10 \%$ fetal calf serum, transferred into 96 -well plates at a final volume of $200 \mu \mathrm{l}$ and grown at $37^{\circ} \mathrm{C}$ in a $5 \% \mathrm{CO}_{2}$ humidified atmosphere for $48 \mathrm{~h}$. Each MTT well contained a 20- $\mu \mathrm{l}$ MTT solution $(5 \mathrm{mg} / \mathrm{ml})$, which was incubated for $4 \mathrm{~h}$. At culture termination, the medium was carefully aspirated and the supernatant discarded. Each well contained $150 \mu$ l dimethyl sulfoxide and was agitated for $10 \mathrm{~min}$ to fully dissolve the crystals. ELISA was used to record the absorbance at $490 \mathrm{~nm}$ and the cellular proliferation rate was calculated as follows: Cellular proliferation rate $(\%)=($ experimental group/absorbance value of blank control group) x 100 .

Flow cytometry (FCM) detection of cell cycle. Trypsinized cells were transfected with plasmids $48 \mathrm{~h}$ following digestion. The cell suspension was then centrifuged in a clean centrifuge tube using a high speed centrifuge (Beijing Era Beili Centrifuge Co., Ltd., Beijing, China) at $507 \mathrm{xg}$ for $5 \mathrm{~min}$. The culture medium was discarded and washed three times with cold PBS. The cells were resuspended by adding $75 \%$ alcohol, fixed for $30 \mathrm{~min}$ in ethanol and centrifuged at $1,917 \mathrm{xg}$ for $5 \mathrm{~min}$, followed by washing three times with PBS. The cells were then resuspended in $100 \mu \mathrm{l}$ PBS and 2.5 $\mu \mathrm{l}$ RNase (10 $\mathrm{mg} / \mathrm{ml})$, followed by $25 \mu \mathrm{l}$ PI pyridine $(10 \mathrm{mg} / \mathrm{ml})$ and staining for $30 \mathrm{~min}$. The cells were examined using a

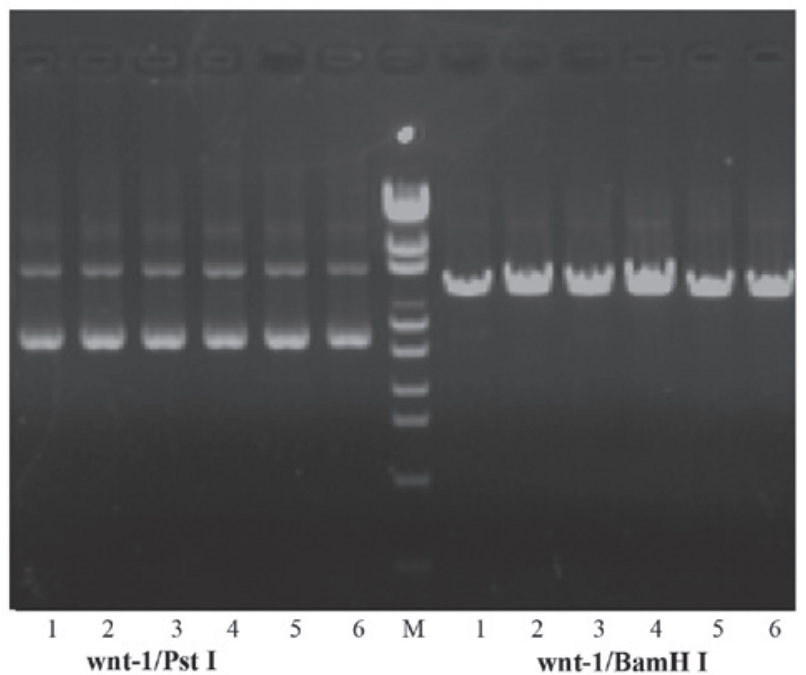

Figure 1. Restriction map of the Wnt-1 plasmid.

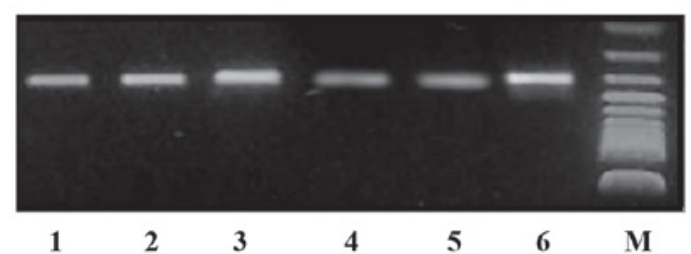

Figure 2. Reverse transcription polymerase chain reaction detection of the Wnt-1 gene mRNA expression levels following plasmid transfection. Lanes: 1, Blank control; 2, negative control; 3, positive control; 4 and 5, transfected pGPU6/GFP/Neo-shRNA-Wnt-1; 6, GAPDH internal reference; and M, 50-bp DNA marker.

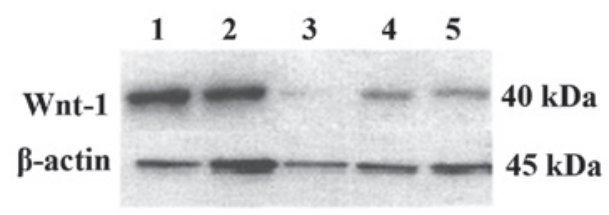

Figure 3. Western blot analysis of the transfected Wnt-1 plasmid. Lanes: 1, Blank controls; 2 , negative controls; 3 , transfected positive controls; and 4 and 5, pGPU6/GFP/Neo-shRNA-Wnt-1 group.

FACSAria flow cytometer (BD Biosciences, Franklin Lakes, NJ, USA) to determine the $\mathrm{G}_{1} / \mathrm{G}_{0}, \mathrm{G}_{2} / \mathrm{M}$ and $\mathrm{S}$ phase fractions.

Statistical analysis. SPSS 10.0 (SPSS Inc., Chicago, IL, USA) was used for analysis of variance. Data are presented as the mean \pm standard deviation. The means between two groups were compared using Student's t-test, while multiple comparisons were analyzed using the F-test. $\mathrm{P}<0.05$ was considered to indicate a statistically significant difference.

\section{Results}

Plasmid verification. Successful digestion by BamHI, but not Pst $\mathrm{I}$ confirmed construction of the recombinant plasmid vector (Fig. 1). Furthermore, sequencing verified that the targeted Wnt 1 gene had been inserted into the pGPU6/GFP/Neo complete shRNA vector. 
Table I. Cell cycle changes of each group (mean \pm standard deviation; $n=4$ ).

\begin{tabular}{lccr}
\hline Group & $\mathrm{G}_{0} / \mathrm{G}_{1}$ phase & $\begin{array}{c}\mathrm{S} \text { phase } \\
(\%)\end{array}$ & $\begin{array}{c}\mathrm{G}_{2} / \mathrm{M} \text { phase } \\
(\%)\end{array}$ \\
\hline Transfection pGPU6/GFP/Neo-shRNA-Wnt-1 & $79.5 \pm 0.6$ & $16.8 \pm 1.0$ & $3.7 \pm 0.5$ \\
Positive control & $78.5 \pm 0.4$ & $11.6 \pm 0.6$ & $10.0 \pm 0.6$ \\
Negative control & $67.2 \pm 1.6$ & $26.5 \pm 0.6$ & $5.6 \pm 1.1$ \\
Blank control & $67.4 \pm 0.7$ & $27.2 \pm 0.4$ & $5.1 \pm 0.5$ \\
\hline
\end{tabular}

The percentage of $U 251$ cells in $\mathrm{G}_{0} / \mathrm{G}_{1}$ phase in the transfection and postive groups was higher than that of the negative control and blank groups $(\mathrm{P}<0.01)$. By contrast, the percentage of $\mathrm{U} 251$ cells in $\mathrm{S}$ phase in the transfection and postive groups was lower than that of the two control groups $(P<0.01)$. No significant difference was identified between the transfection and postive groups in $G_{0} / G_{1}$ phase or $S$ phase $(P>0.05)$.

RT-PCR detection of Wnt-1 gene mRNA expression level changes following RNAi. Transfected cells were characterized by semi-quantitative RT-PCR $48 \mathrm{~h}$ following transfection to detect the pGPU6/GFP/Neo-shRNA-Wnt-1-positive cells. The Wnt -1 mRNA content had decreased by $63 \%$ compared with the controls, while the negative and positive control groups did not exhibit any significant differences (Fig. 2). Compared with the controls, no significant differences in Wnt-1 gene mRNA expression levels were observed between the negative and positive control group (99 and 100\%, respectively).

Knockdown of Wnt-1 protein expression by plasmid transfection. Western blot analysis showed that the Wnt-1 protein expression was significantly reduced following transfection. Although the negative control did not change significantly, the expression of the positive control decreased. This may be the result of excessive cell death, which reduced the amount of extracted protein (Fig. 3).

MTT cell proliferation assay. The results of the MTT assay indicated that the positive and negative controls exhibited decreased cell growth following pGPU6/GFP/Neo-shRNA-Wnt-1 transfection. The positive controls that were transfected with pGPU6/GFP/Neo-shRNA-GAPDH showed decreased cell survival compared with the pGPU6/GFP/Neo-shRNA-Wnt-1 transfected samples, however, survival at $48 \mathrm{~h}$ was not identified to be statistically significant.

FCM test results. No statistically significant differences were identified between the positive and negative control groups at $48 \mathrm{~h}$ post-transfection $(\mathrm{P}>0.05)$, which indicated that the plasmid and transfection reagents were not toxic. The positive controls transfected with pGPU6/GFP/Neo-shRNA-Wnt-1 were predominantly arrested at $G_{0} / G_{1}$ and the number of cells in the $\mathrm{S}$ phase was decreased $(\mathrm{P}<0.05)$. Furthermore, the number of replicating cells decreased, which indicated that U251 proliferation was inhibited (Table I).

\section{Discussion}

The Wnt signaling pathways are important in cellular differentiation and proliferation in a variety of species, and are involved in the formation of certain types of tumor (11-13). The $W n t / \beta$-catenin signaling pathway is considered to be a classical signaling pathway, which has been investigated in-depth (14). Wnt signal transduction mediates other processes, including $W n t / \mathrm{Ca}^{2+}$ signaling, planar cell polarity, spindle orientation and asymmetric cell growth $(11,14)$. Wnt binding of the Frizzled receptor inhibits the effect of glycogen synthase kinase 3- $\beta$, axin, and adenomatous polyposis coli protein complexes that are involved in $\beta$-catenin phosphorylation and degradation. Non-phosphorylated $\beta$-catenin is not degraded, however, accumulates in the cytoplasm, prior to translocation to the nucleus. $\beta$-catenin then binds to the lymphocyte enhancer factor/T cell-specific transcription factor, activating the target genes, $c$-myc, cyclin D and MMP7, leading to cellular proliferation and tumor formation. Therefore, certain studies have hypothesized that targeted therapy of Wnt signaling may inhibit tumor formation and growth (15).

Gliomas are the most common type of primary intracranial tumor and more effective therapeutic strategies are required to stop glioma progression. The $W n t / \beta$-catenin signaling cascade is an important signal transduction pathway in human cancer (16). The human Wnt family consists of 19 members that regulate cell proliferation, differentiation, motility and fate during embryonic development and tumorigenesis. Wnt members bind to the cell surface receptors, Frizzled and low density lipoprotein receptor-related protein, and transduce their signals through $\beta$-catenin-dependent and -independent intracellular signaling pathways (17). Wnt-1 was one of the first signaling molecules to be identified and it is considered to be the first step in the classical $W n t / \beta$-catenin signaling pathway $(18,19)$. Increasing evidence indicates that interplay between the Wnt/ $\beta$-catenin and PI3K/AKT signaling cascades is involved in tumor development and progression. However, the mechanism of this in glioma is not well understood (20). Although a number of studies have identified a variety of tumors that exhibit abnormal Wnt-1 expression $(1,10)$, abnormal expression is rare in glioma. In our previous study, it was demonstrated that Wnt- 1 gene expression is increased in glioma, with little or weak expression identified in normal brain tissue. Furthermore, Wnt-1 expression showed a positive correlation with the glioma grade (15). The present study indicated that targeting Wnt-1 gene expression by RNAi knockdown inhibits the growth of human glioma cells. This demonstrates that glioma growth may be closely correlated with Wnt-1 protein expression. Malignant glioma growth may involve activation of the Wnt-1 signaling pathway (21), 
however, the specific underlying mechanism requires further investigation (22).

Current RNAi methods are important for investigating gene function $(18,23,24)$ and it is hypothesized that the Wnt signaling pathway may be ideal for targeted drug development. However, few studies have used Wnt-1 gene RNAi. Certain studies have used fragments of chemically synthesized siRNA in transfected cells $(25,26)$, or plasmids lacking a reporter gene (27), which complicates the assessment of transfection efficiency and the identification of stable cell lines. A previous study described the transfection of siRNA targeting Wnt-1 into SH-SY5Y neuroblastoma cells using Lipofectamine $^{\mathrm{TM}} 2000$ (28). Wnt-1 and $\beta$-catenin protein expression decreased following transfection with siRNA, as did the cell number, and was accompanied by abundant floating dead cells. Additionally, the SH-SY5Y cells transfected with siRNA targeting Wnt-1 showed less viability.

In conclusion, the current study used a pGPU6/GFP/Neo carrier plasmid containing a GFP reporter, which detects cellular expression efficiency and Kanamycin/G418 resistance, into stable cell lines. Therefore, siRNA targeting Wnt- 1 was used to investigate which region of the Wnt-1 gene may be targeted as a novel hotspot (29). The results of the present study revealed that miR-106a-5p is a tumor suppressor gene in astrocytomas. The overexpression of miR-106a-5p inhibits astrocytoma cell proliferation, migration, and invasion and promotes apoptosis. In addition, FASTK was found to be a direct target for miR-106a-5p. Although much remains to be elucidated in terms of the role of miR-106a-5p in the pathogenesis of astrocytomas, miR-106a-5p presents a novel potential therapeutic target for the treatment of astrocytomas.

\section{References}

1. Benad P, Rauner M, Rachner TD and Hofbauer LC: The anti-progestin RU-486 inhibits viability of MCF-7 breast cancer cells by suppressing WNT1. Cancer Lett 312: 101-108, 2011.

2. Benchabane H, Xin N, Tian A, et al: Jerky/Earthbound facilitates cell-specific Wnt/Wingless signalling by modulating $\beta$-catenin-TCF activity. EMBO J 30: 1444-1458, 2011.

3. Xu X, Sun PL, Li JZ, Jheon S, Lee CT and Chung JH: Aberrant Wnt $1 / \beta$-catenin expression is an independent poor prognostic marker of non-small cell lung cancer after surgery. J Thorac Oncol 6: 716-724, 2011.

4. Nakashima N, Huang CL, Liu D, Ueno M and Yokomise H: Intratumoral Wntl expression affects survivin gene expression in non-small cell lung cancer. Int J Oncol 37: 687-694, 2010.

5. Oguma K, Oshima $\mathrm{H}$ and Oshima M: Inflammation, tumor necrosis factor and Wnt promotion in gastric cancer development. Future Oncol 6: 515-526, 2010.

6. Fracalossi AC, Silva Mde S, Oshima CT and Ribeiro DA Wnt/beta-catenin signalling pathway following rat tongue carcinogenesis induced by 4-nitroquinoline 1-oxide. Exp Mol Pathol 88: 176-183, 2010.

7. Wang FL, Guo X, Yuan TZ, et al: Expression and clinical significance of Wnt-1 and beta-catenin in nasopharyngeal carcinoma. Ai Zheng 28: 72-75, 2009.
8. You L, Kim J, He B, Xu Z, McCormick F and Jablons DM: Wnt-1 signal as a potential cancer therapeutic target. Drug News Perspect 19: 27-31, 2006.

9. Augustin I, Goidts V, Bongers A, et al: The Wnt secretion protein Evi/Gpr177 promotes glioma tumourigenesis. EMBO Mol Med 4: 38-51, 2012.

10. Natsume A, Kinjo S, Yuki K, et al: Glioma-initiating cells and molecular pathology: implications for therapy. Brain Tumor Pathol 28: 1-12, 2011.

11. Ille F and Sommer L: Wnt signaling: multiple functions in neural development. Cell Mol Life Sci 62: 1100-1108, 2005.

12. Toledo EM, Colombres M and Inestrosa NC: Wnt signaling in neuroprotection and stem cell differentiation. Prog Neurobiol 86: 281-296, 2008.

13. Han L, Yang Y, Yue X, et al: Inactivation of PI3K/AKT signaling inhibits glioma cell growth through modulation of $\beta$-catenin-mediated transcription. Brain Res 1366: 9-17, 2010.

14. Reya T and Clevers H: Wnt signalling in stem cells and cancer. Nature 434: 843-850, 2005.

15. De Ferrari GV and Moon RT: The ups and downs of Wnt signaling in prevalent neurological disorders. Oncogene 25: 7545-7553, 2006

16. Liu C, Tu Y, Sun X, et al: Wnt/beta-Catenin pathway in human glioma: expression pattern and clinical/prognostic correlations. Clin Exp Med 11: 105-112, 2011.

17. Kamino M, Kishida M, Kibe T, et al: Wnt-5a signaling is correlated with infiltrative activity in human glioma by inducing cellular migration and MMP-2. Cancer Sci 102: 540-548, 2011.

18. Thiele S, Rauner M, Goettsch C, et al: Expression profile of WNT molecules in prostate cancer and its regulation by aminobisphosphonates. J Cell Biochem 112: 1593-1600, 2011.

19. Sharma V, Dixit D, Koul N, Mehta VS and Sen E: Ras regulates interleukin-1 $\beta$-induced HIF-1 $\alpha$ transcriptional activity in glioblastoma. J Mol Med (Berl) 89: 123-136, 2011.

20. Chen L, Huang K, Han L, et al: $\beta$-catenin/Tcf-4 complex transcriptionally regulates AKT1 in glioma. Int J Oncol 39: 883-890, 2011.

21. Wei W, Chua MS, Grepper S and So SK: Blockade of Wnt-1 signaling leads to anti-tumor effects in hepatocellular carcinoma cells. Mol Cancer 24: 76, 2009.

22. Sareddy GR, Challa S, Panigrahi M and Babu PP: Wnt/beta-catenin/Tcf signaling pathway activation in malignant progression of rat gliomas induced by transplacental N-ethyl-N-nitrosourea exposure. Neurochem Res 34: 1278-1288, 2009.

23. Whangbo JS and Hunter CP: Environmental RNA interference. Trends Genet 24: 297-305, 2008.

24. Dillin A: The specifics of interfering RNA specificity. Proc Nat Acd Sci USA 100: 6289-6291, 2003.

25. Mikami I, You L, He B, et al: Efficacy of Wnt-1 monoclonal antibody in sarcoma cells. BMC Cancer 5: 53, 2005.

26. Wieczorek M, Paczkowska A, Guzenda P, Majorek M, Bednarek AK and Lamparska-Przybysz M: Silencing of Wnt-1 by siRNA induces apoptosis of MCF-7 human breast cancer cells. Cancer Biol Ther 7: 268-274, 2008.

27. Polanec J, Pavelic ZP and Myers WL: Effect of Wnt-1 antisense RNA on the outgrowth of a mammary adenocarcinoma cell line expressing that oncogene. Clin Mol Pathol 49: M166-M169, 1996.

28. Zhang L, Li K, Lv Z, Xiao X and Zheng J: The effect on cell growth by Wnt1 RNAi in human neuroblastoma SH-SY5Y cell line. Pediatr Surg Int 25: 1065-1071, 2009.

29. Takahashi-Yanaga F and Sasaguri T: The Wnt/beta-catenin signaling pathway as a target in drug discovery. J Pharmacol Sci 104: 293-302, 2007. 